\title{
LA CARIES DENTARIA EN LOS NINOOS
}

Algunos concentos profilácticos $y$ complicaciones de las caries de 4. grado.

\author{
POE 1 DK. CARLOS TAPIA DEPASSIER. \\ Pookest Exteardinario di Clinia Dintil Infantil.
}

No es mi ánimo presentar un trabajo acabado, sino el presentar algunos casos en que ha intervenido la Clínica lnfantil de la Escuela Dental a ni cargo, que bien pueden complementar el tema traído por el Dr. De la Maza.

Voy a referirme primero a la caries dentaría en el niño y algunos conceptos modernos sobre la profilaxia de clla.

Si consideramos que el desarrollo normal de los dientes, sin ser un preventivo absoluto contra la caries, ofrece una mayor resistencia contra ella, resulta de toda evidencia que la profilaxia debe empezar procurando influir en el me. tabolismo durante la formación y desarrollo de los dientes, para que sean normales.

Hemos considerado que el tratamiento onetatorio de la saries solamente. no sería sino un tratamiento sintomático por decir asi, ya que la caries no podemos considerarla como un fenómeno local aislado sino como un complejo de aspecto general y local.

Es por esto que la profilaxia de la caries no podemos apartarla de su etiología y estudiando las causas predispotientes locales y generales, podemos dar normas destinadas a contrarrestarlas.

Considerando que el diente empieza su calcificación en la $20 . "$ semana de la vida intrauterina, con los incisivos de la 1." dentición: proceso de calcificación que acompaña a toda la vida fetal y a los primeros 20 años de la vida, en ella se traducirán las condiciones alimenticias de la madre encinta. de la nodriza y de las $1 .{ }^{3}$ y $2 .^{a}$ infancias.

Los cuidados profilácticos los estudiaremos entences en 3 períodos: prenatal, lactancia y $1 .^{*}$ y $2 .{ }^{*}$ infancias. 
Período pre-natal.-El feto de término trae calcificadas todas las coronas de los dientes temporales (o de leche) y aun, una de las cúspídes del primer molar permanente (molar de 6 años), luego la profilaxia de la primera dentición hay que empezarla en la madre encinta, suministrándole una alimentación rica en sales (Ca, P, K, Na, Fe, etc.).

Respecto al calcio debemos tener presente que la madre además de sus necesidades diarias, (1 gramo) debe suministrar al feto a partir del 7.9 mes, 0,63 gr. diario.

Procuraremos además, que la dieta sea rica en vitaminas, especialmente A, ᄃ, y D, por lo que respecta a la calcificación.

No entraremos en detalles sobre estos capítulos que Uds. dominan mejor que nosotros.

Quiero recalcar si, la importancia de las experiencias de Verzar, investigador húngaro, sobre la absorción intestinal y en las que llama la atención el gran valor que asigna a la dieta rica en grasas animales, ya que los ácidos grasos en unión con los ácidos biliares juegan un papel tanto o más importante que la vitamina $D$ standardizada en la absorción fósforo-cálcica.

Otro punto que quería recalcar es el relativo a los glicidos. La dieta no debe contener más de un $50 \%$ del valor calórico proveniente de ellos. Dietas muy ricas en glúcidos son descalcificantes, ya que retiran P. sanguíneo para metabolizarse (Experiencias Prof. Honorato, Escuela Dental).

De gran importancia es enseñar a las madres que si su dieta es catenciada, la calcifícación de los dientes temporales de su hijo, será defectuosa y tendrá por ésto, poca resisten. cia a la caries. Otro punto que también hay que recomendarles es el cuidado del intestino de modo que sus paredes estẹ́n siempre en estado óptimo para la absorción de las sales.

La calcificación artificial, tanto de la madre como del miño, consideramos que debe ser guiada por el especialista. ya que no es fácil la absorción fósforo-cálcica. Sabemos que el Ca. con el P. en el intestino, dan fosfato de calcio insolu. ble, si no hay un $\mathrm{pH}$. óptimo para su absorción.

La máxima absorción del P. se obtiene con los fostatos minerales ácidos y entre éstos, los más absorbidos son los de sodio.

La calcificacion por via parenteral es un tanto delicada si se hace un tratamiento prolongado, pudiendo acartear el procesn inverso, segun ha llamado la atención el Prof. Craz Coke. 
El exceso de vitamınas standardizadas también tıene sus peligros.

El cuidado de la boca de la madre debe extremarse en este estado. Obturar sus caries, extracción raíces y focos sépticos; limpieza del tártaro. Es frecuente encontrar alteraciọn de los tejidos peri-dentarios durante el embarazo, que nejoran con la extracción del târtaro y el saministro de vitamina $C$.

El Profesor Monckeberg cree que muchos abortos podrían atribuitse a una toxemia de origen focal dentario.

Período de lactancia.- I a madre debe criar a su hijo al pecho no sólo por la importancia de la leche materna que Uds. saben mejor que nosotros, sino que considerado bajo el punto de vista del estomatólogo. La succión del seno materno contribuye al desarroflo de los músculos de la cara. al desarrollo de los maxilares y la armonía del rostio en general.

Cuando la alimentación materna no sea posible, aconsejamos y propagamos que el pediatra debe ser quién dictamine y guie la alimentación que haya de remplazarla.

Así evitaremos los errores alimenticios tan comunes, yue traen fenómenos de carencia u trastornos entero-cólicos.

Casi todos los niños que hemos examinado en la Clínica Infantil, con el concurso del Dr. De la Mazo y que han sufrido de trastornos intestinaies prolongados durante la Iactancia y $1 .{ }^{*}$ infancia, presentan procesos hipoplásicos o ca. ries múltiples en su $2 .^{*}$ dentición.

En el período dz las $10^{*}$ y $2 *^{*}$ infancias.-Los cuidados profilácticos generales deberán encaminarse también en el sentido de prescribir la dieta de acuerdo con las reglas alimenticias conocidas.

El cuidado de ía boca debe empezar desde que el niño completa su $1 .^{\text {a }}$ dentición, vale decirr después de los 2 años $\mathrm{y}$ debe visitar al odontólogo especialista en forma periódica para que diagnostique y trate a tiempo las caries incipientes, evitando asi los peligros de las complicaciones que veremos más adelante.

Factores locales que favorecen Ia caries.-Considerados los factores generales que disminuyen la resistencia de los dientes a la caries, ya sean éstas causas patológicas o alimenticias, debemos tener presente el factor local y es éste, el factor microbiano.

Es un hecho indiscutible que la $1 .^{\circ}$ fase de la caries, esto es, la destrucción de los tejidos duros del diente, la efectúan los bacilos acidófilos, que mediante la placa bacteriana se fi. 
jan en los puntos de retención del esmalte, tales como imperfecciones en su extructura, surcos muy acentuados o partes del diente que quedan libres de la acción mecánica de la lengua y de la masticación (espacios interdentarios).

En el Laboratorio de Bacteriología de la Escuela Dental a cargo del Prof. Felipe González A., el ayudante dentista Dr. Beltramín. llevó a cabo interesantes experiencias in vivo $e$ in vitro sobre estos bacilos, llegando a la conclusión que en toda caries dentaria se encuentra un bacilo Gram positivo que aumenta su frecuencia en planos profundos de la caries, de poder altamente acidificante y que es capaz de producir a corto plazo en dientes sanos extraídos y sumergidos en un cultivo de él, fenómenos semejantes en todo a la caries humana.

De aquí la necesidad de eliminarlo de la boca, median. te el escobillaje y enjuagatorios alcalinos, especialmente en la noche.

Los hidratos de carbono, mediante los fermentos amilolíticos que producen sus residuos y la producción de ácidos (láctico, pirúvico) favorecen el desarrollo de los acidófilos.

Es conveniente suprimir la alimentación muy molida que además de dejar grandes residuos en la boca no ejercita la función masticatoria, necesaria a la salud de los dientes y tejidos peri-dentarios por su actividad circulatoria.

Muchos autores han dado la importancia que tiene la función masticatoria, notando la degeneración de los dientẹs y alvéolos cuando no se ejercita. Esta tendencia a degenerar del aparato masticatorio se transmite por herencia.

El Prof. Bolk de Amsterdam prevé en el futuro uná nueva fórmula dentaria de 24 dientes, debido a la falta de la función masticatoria.

Nosotros hemos observado que sólo un pequeño porcentaje de personas tiene 32 dientes, es decir, el molar del juicio muy rara vez evoluciona en forma normal debido a falta de espacin mandibular o degeneración en su forma y tamaño.

Hasta aquí, un iggero vistazo. como abordamos hoy en tuestra Escuela Dental, la profilaxia dental.

Nos ocuparemos en seguida, de las caries en el niño y especialmente de los 4 .os grados en los dientes tempotales $y$ sus complicaciones.

Caries de 4.9 grado en dientes temporales.- $-\mathrm{El}$ diente temporal tiene una estructura y morfología un tanto diversa del diente permanente, de ahí que la anatomía patológica de sus lesionese obedezcan a una modalidad también diversa. 
Por estudios clínicos a histológicos que hemos practicado en nuestra Clínica Infantil sobre la pulpa del diente

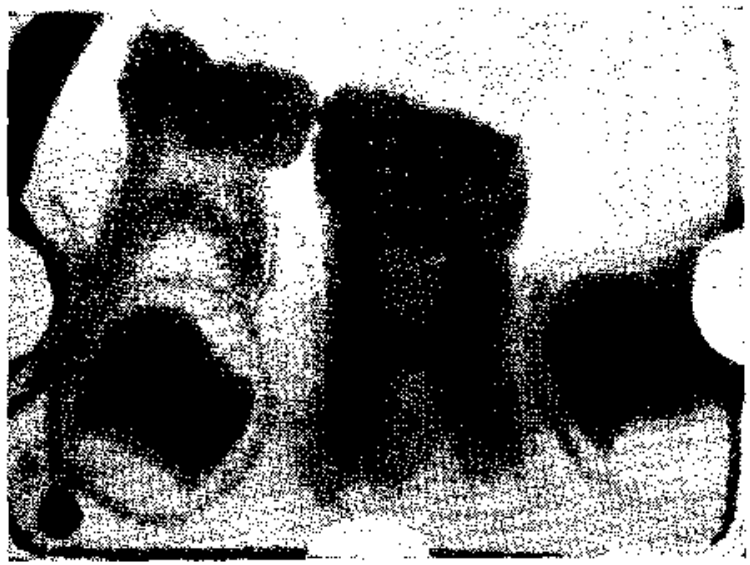

FIG. 1

Saco dentario sano.



FIG, 2

Cusito grato del segundo malar de leche con osteitis y compromiso klis saco derrario del premolar permanente.

temporal, hemos podido observar que en el período de su reabsorción radicular, ella sufre una regresión en la estrur. 
tura tisular consistente en una degeneración fibrosa y vacuolar, aumento de la capilaridad sanguínea y atrofia de sus filetes nerviosos.

En las caries de $2 .^{\circ}$ grado, la propagación de la infección a través de la dentina que es más delgada que en el diente permanente y mucho más porosa, se hace con mucha rapidez hacia la pulpa. Esta, a su vez, es afectada en su vitalidad rápidamente, dadas las escasas defensas que tiene un tajido en regresión.

Producido el compromiso pulpar, la gangrena sobreviene rápidamente, como asimismo el compromiso óseo a través del conducto radicular.



FIG. 3

Cuartos grados tratados (dientes temporales).

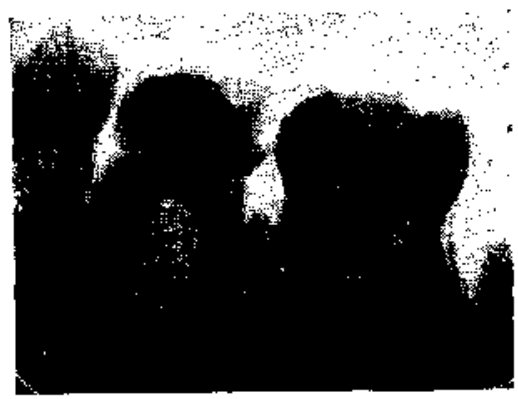

FIG. 4

Cuartos grados tratados (dientes temporales).

El tejido óseo que media entre el diente temporal y el de reemplazo es un tejido muy vascularizado $y$ con elementos celulares, como las células gigantes mono y polinucleadas que tienen una acción osteoclásica para las raíces del diente temporal.

Considerando ia mayor vascularización de este tejido es fácil explicar la gran extensión y rapidez de estas osteitis. En los molares estas osteitis se extienden inter-radicularmen. te $y$ son. como es de suponer, $\mu$ n grave peligro para el saco dentario que envuelve el diente de reemplazo muy próximo al foco $y$ es muy frecuente $s u$ infección (peri-coronitis) con funestas consecuencias futuras para la estructura del esmaite de este diente en evolución.

Todo este cuadro nos hace pensar seriamente en el tratamiento a tiempo de las caries de los dientes temporales. Si 
así no fuera posible, ya sea por lenidad de los padres, indo. lencia del profesional o rebeldía del pequeño paciente u otras causas, debemos abocarnos al tratamiento o extracción de la pieza temporal ya complicada, pero en ningún caso el abandono total.

Para su tratamiento debemos tener presente: la vecin.. dad de la época de su reemplazo, la mayor o menor destruc. ción de su corona y antes que todo, el estado general del paciente.

En el niño con buen estado nutritivo es posible practicar el tratamiento radicular de estos dientes.

En nuestras estadísticas clinicas de la Escuela Dental, tenemos casos de 4 .os grados y aun con complicaciones, que han cedido a nuestros tratamientos. Tenemos radiografías de casos de osteitis inter-radiculares de molares en que prueban la curación de la región afectada.

Cuando se haya aconsejado la extracción de la pieza y la época de reemplazo por el diente permanente esté distante, es muy recomendable la colocación de aparatos retenedores de espacio para la correcta erupción de este último.

Un diente infectado, abandonado a sí mísmo, pasa a ser un foco altamente tóxico para el niño, como lo demuestran los casos presentados por el Dr. De la Maza.

Llama la atención, en muchos de los casos registrados. de infección focal dentaria, la rapidez con que se hacen tóxi$\cos$, focos de cronicidad reciente de un diente temporal.

Someto a la consideración de los señores médicos pediatras esta ligera exposición, con mis agradecimientos muy sinceros por el honor que me han dispuesto al escucharme. 